\title{
URBAN ROAD PRICING AND SUSTAINABLE TRANSPORTATION SYSTEMS: THE THESSALONIKI CENTRAL AREA CASE
}

\author{
S. BASBAS \& I. POLITIS \\ Department of Transportation and Hydraulic Engineering, School of Technology, Faculty of Rural and Surveying \\ Engineering, Aristotle University of Thessaloniki, Thessaloniki, Greece.
}

\begin{abstract}
Urban road pricing involves direct charging of drivers for the use of the road network, usually during peak periods. The main objectives for the introduction of a road pricing scheme, in a congested city network, include reduction of delays, environmental improvement and revenue increase. These objectives are closely associated with the concepts of sustainable mobility in urban areas with respect to social equity, economic efficiency and environmental responsibility. This paper attempts to estimate the potential interrelation between urban road pricing and sustainable mobility management policy by modelling the impacts (traffic network operation, environmental indices and revenue) of a hypothetic implementation of cordon tolls in the city centre of Thessaloniki (situated in northern Greece), which faces severe traffic and environmental problems. The evaluation was carried out using the SATURN traffic simulation model, which was developed at the Institute for Transport Studies, University of Leeds, UK. SATURN is a well-known transport analysis model which is widely used. In order to assess the impacts of traffic scenarios, the software runs a simulation-assignment procedure simultaneously using commonly accepted algorithms that originate from transport theory such as all-or-nothing assignment, Wardorp's principles. The road network used in SATURN for the purposes of this research consists of 813 nodes and 293 zones. Furthermore, an analysis was carried out regarding the contribution of the extracted model indicators to the establishment of an overall strategy concerning sustainable transportation and mobility in Thessaloniki's central area. Various scenarios were examined depending on the year of the analysis and the alternative transport mode in use. These scenarios were compared with different road charging scenarios. Parameters such as traffic volumes, speed, vehicle emissions were estimated. A comparative analysis of these values in conjunction with the definition of sustainable mobility and development in general was performed, concluding that innovative measures can reassign the trip patterns in urban areas, thereby improving the transport system operation in terms of sustainability. Undoubtedly, the use of powerful assessment tools such as SATURN for the evaluation of the impacts of various Transportation Demand Management measures like road charging will provide valuable assistance to policy makers and the transportation planners involved in the specific process.

Keywords: road pricing, sustainable transportation systems, Transportation Demand Management.
\end{abstract}

\section{INTRODUCTION}

There is a general agreement nowadays that the level of service of the transport system significantly affects the daily life of people worldwide. The problem becomes more important in the case of urban central areas due to the fact that transport demand exceeds transport supply. Among the key factors of the problem in central urban areas is the constant increase in the number of passenger cars, the large number of daily trips made by passenger cars, the quite often insufficient operation of the public transport system, the high population and building density, the limited number of parking lots, etc. Therefore, it is obvious that demand plays a dominant role because it is not always easy to improve supply due to technical constraints (e.g. limited space for new infrastructure) and budget availability. This is the reason why an extensive effort has been made during the last few years in order to redistribute the transport demand in central urban areas.

Various measures have been implemented in central congested road networks in order to deal with the demand. These measures, known as Transportation Demand Management (TDM) measures, 
include High-Occupancy Vehicle lanes, High-Occupancy Toll (HOT) lanes, bus lanes, parking pricing, etc. TDM measures can support the effort towards a sustainable transportation system. Although there is a growing global interest in the concepts of sustainability, sustainable development and sustainable transport, there is no universally accepted definition for these terms.

An accurate definition originates from the European Union Council of Ministers of Transport. According to this definition, a sustainable transportation system is one that [1]:

1. allows the basic access and development needs of individuals, companies and society to be met safely and in a manner consistent with human and ecosystem health, and promotes equity within and between successive generations;

2. is affordable, operates fairly and efficiently, offers a choice of transport modes, and supports a competitive economy, as well as balanced regional development;

3. limits emissions and waste within the planet's ability to absorb them, uses renewable resources at or below their rates of generation, and uses non-renewable resources at or below the rates of development of renewable substitutes, while minimizing the impact on the use of land and the generation of noise.

Taking the above definition into account, it can be easily concluded that sustainable development is a very complex concept involving several interrelated issues which can be grouped into three major categories (also known as the three Es): economic, social equity and environmental issues, as indicated in Table 1.

It is clear that if any measure, action or policy in general, satisfies many - or, in a theoretical manner, all - of the subcategories listed in Table 1, then the goal of sustainable planning is achieved, which is the objective of this paper - the potential design, installation and operation of an urban toll application in the city of Thessaloniki.

Moreover, another classification can be made according to the area of the implementation. In this case, there are two spatial levels of sustainable development: the global, concerning long-term stability of the earth's environment and availability of resources to support human activities; and the local, concerning localized forms often related to urban areas in terms of jobs, housing, land use, efficient mobility and environmental pollution.

New trends indicate that sustainable transportation policy should take into consideration the larger 'environment' in which the transportation activity is embedded. This approach acknowledges the interaction between transportation and other social and economic systems, taking into account that, in the transport sector, different groups may consume different resources. The complexity of improving the operation of a transportation system, towards a sustainable approach, is also supported by the fact that changes in the transportation system are linked to changes in human behaviour.

Table 1: The three categories of sustainability issues [2].

\begin{tabular}{lll}
\hline Economic & \multicolumn{1}{c}{ Social } & \multicolumn{1}{c}{ Environmental } \\
\hline Affordability & Equity & Pollution prevention \\
Resource efficiency & Human health & Climate protection \\
Cost internalization & Education & Biodiversity \\
Trade and business activity & Community & Precautionary action \\
Employment & Quality of life & Avoidance of irreversibility \\
Productivity & Public participation & Habitat preservation \\
\hline
\end{tabular}


Unfortunately these two parameters are usually overlooked by analysts in their policy assessments, leading finally to unsuccessful and unsustainable implementation strategies.

Various theories have been developed in order to enclose this expanded 'environment' to policy makers' analysis. One interesting theory was presented by Goldman and Gorham [3]. They identified four emerging clusters of innovative directions that outline potential visions of sustainable transport: new mobility, concerning how individuals plan their daily activities; city logistics, which addresses the efficient operation of urban freight traffic; intelligent system management, which examines the relationship between urban infrastructure and sufficient operation; and livability, regarding society's interaction with transportation systems, including concerns about accessibility, the allocation and design of public space, opportunities for social engagement and recreation, etc.

It is important to underline the need for an integrated comprehensive planning which includes strategies that accomplish multiple objectives and avoids those that solve one transportation problem but exacerbate others. These solutions, which on one hand reduce the traffic and associated environmental impacts, such as traffic congestion, pollution, crashes and consumer costs, and on the other hand increase mobility options for non-drivers, and encourage more efficient land use and modal split patterns, are also known as Win-Win Transportation Solutions [2, 4]. Within the framework of this integrated comprehensive planning, the above-mentioned TDM measures, such as road pricing, can play a substantial role in reducing the negative impacts of transport systems operation.

The main objectives of an integrated transport pricing policy is 'to enable environmental improvements, alleviate congestion and facilitate cost recovery through optimising modal split and improving intermodality by means of internalising the external costs of transport' [5].

A number of TDM measures, known as pricing methods, include charging for the use of transport infrastructure. Several TDM strategies that involve pricing are Road Pricing, Public Transit, Parking Pricing, Distance Based Charges, etc.; these are coupled with high technology applications related to collecting fees, online charge information and vehicle distance counting.

Different types of road pricing are Road Tolls, Congestion Pricing, Cordon (Area) Tolls, HOT Lanes, Pay-As-Drive-Vehicle Insurance, etc. Cordon Tolls are fees paid by motorists to drive into particular areas, usually city centres, especially during peak periods, such as weekdays. Cordon Tolls could be the most likely choice of road pricing in the near future, because although they do not perfectly reflect the marginal social cost of travelling within the congested city central area, they are cheaper to install and operate than the more sophisticated alternatives, easier for the public to understand and likely to yield higher net benefits than other systems [4]. These parameters are also closely linked with the European Commission's requirements for efficient and fair pricing, as it was described in the Green Paper publication 'Towards Fair and Efficient Pricing in Transport: Policy Options for Internalising the External Costs of Transport in the European Union' (December 1995) and in the White Paper directive 'Fair Payment for Infrastructure Use: A Phased Approach to a Common Transport Infrastructure Charging Framework in the EU' (July 1998).

Lastly, another main issue concerns the designing of the pricing system in relation to the city's spatial structure. It is proved [6] that monocentric cities with large density topography, such as the city of Thessaloniki, tend to achieve larger welfare gains under cordon pricing than those cities that are sparser. Of course, the structure of the city reflects citizens' activities and also their travel behaviour.

\section{METHODOLOGY OF THE STUDY}

\subsection{Description of the case study area}

The study area is the central area of the city of Thessaloniki. The city is situated in northern Greece and has a population of approximately 1,000,000 inhabitants. The road network of the city centre is 
congested during the morning and evening peak periods and as a result delays are observed for the vehicles directed to this specific area. Approximately 1,600,000 trips are made daily in the city according to the General Transportation Study (GTS) of the Thessaloniki Metropolitan Area, which was completed in 1999. It is very important at this point to underline the fact that almost $25 \%$ of these trips use the city centre as their origin or destination (or both). As a result, traffic and associated environmental problems related with delays, vehicle queues, energy consumption and pollutants emissions have been observed [7].

The public transport system in Thessaloniki includes the Urban Transport Organisation of Thessaloniki (OASTH) which is the only bus operator for urban transport. OASTH operates 68 bus lines daily in its network with 505 buses (out of a total of 536 buses). The number of passengers served annually by this fleet is approximately 150,000,000 [8]. A metro system has also been planned to be constructed in May 2006 (which is expected to be completed in the year 2012) and its cost will be 1 billion euros. The metro system will cover a distance of $9.5 \mathrm{~km}$ and is expected to serve around 250,000 passengers per day. Another major transport project, which will be constructed, is the submerged tunnel. The tunnel will bypass the city centre by the seaside and will offer the opportunity to implement a revitalization scheme in the city centre. The tunnel is expected to have tolls. It must be mentioned at this point that, for the time being, the only example of urban tolls in Greece is the case of Attiki Odos (Attika Tollway) in Athens. Both these transport infrastructure projects aim to improve the traffic and environmental conditions, mainly in the city centre and its greater area. The benefits can be maximized if an integrated road pricing scheme is implemented in the city centre (Cordon Tolls). This has been proved in various cities all over the world, which implemented different types of congestion pricing, e.g. Singapore, Orange County (California State Route 91), London, Trondheim and Oslo [9-12].

The butterfly-like shape of the city of Thessaloniki is considered to favour a congestion pricing scheme. A possible obstacle to the success of project has to do with the fact that people are not used to paying for the use of road infrastructure in the country (except the national highway) and they might question the benefits of such a scheme. The operation of the submerged tunnel, which will impose tolls on its users, could be considered as a test of people's response towards the implementation of urban tolls in the city centre.

\subsection{Traffic and road user charges modelling}

The traffic simulation model used for the purposes of the present research was the Simulation and Assignment of Traffic to Urban Road Networks (SATURN), which is a suite of flexible network analysis programs developed at the Institution for Transport Studies, University of Leeds, UK. SATURN is a tactical transport model that estimates the traffic volume on each link of a road network assuming a fixed trip matrix. Its very detailed representation of the road network and the modelling of turning movements at junctions distinguish this type of model from assignment models used to model strategic transport [13].

SATURN requires two basic sets (files) of input data. The first file includes the road network data, which represents the geometrical description (e.g. links length, number of links at the node, number of entry lanes for each link, toll charges) and traffic information (e.g. traffic signal data, minimum gap for give-away turns at priority junctions and roundabouts, free flow speeds, saturation flows for each turn) of a node. For Thessaloniki's representation network, two levels were used, with an inner simulation network containing analytical data about road links and junctions, and a buffer network (surrounding the simulation network) in order to simulate trips with origin or destination outside the metropolitan area. 
The second file represents the trip matrix, also known as origin-destination table, and expresses the demand for travel through the number of trips between the pairs of zones, as indicated by the GTS in 1999. Bus or subway trips are not included in the trip matrix file; they are included in the network data file because they follow fixed routes and cannot participate in the assignment procedure. The road network used in SATURN for the purposes of this research consists of 813 nodes and 293 zones (Fig. 1).

Cordon Tolls are defined in SATURN as a (momentary) charge per 'link', where link in this context includes simulation turns, centroid connectors and special road segments like bridges, tunnels. After the evaluation of the impacts on modal split (how tolls affect the travel behaviour), Cordon Tolls are simply one extra component in the definition of the generalized cost. In this sense, they influence route choice within the assignment, as well as the minimum origin-destination costs used within elastic or variable demand assignment. After version 10.3 of SATURN, the conversion from momentary tolls to generalized time is achieved through functions, which are given by the program according to a computed generalized network time [13].

\subsection{Input data and calibration of the model}

Table 2 presents the specific attributes of the road charging implementation trial, according to the specific characteristics of Thessaloniki's urban road network.

The fee collection and enforcement services could be materialized simultaneously through specific telematics applications (Automatic Toll Collection Systems (ATCS)) and the Automatic Number Plate Recognition (ANPR) technology. These implementations seem to have significant results in other cities like London and Singapore [9, 11].

The fee of 2.2 euro originates from a European project called TransPrice, co-funded by the European Commission Directorate-General for Transport. TransPrice aimed to address the issues of integrated

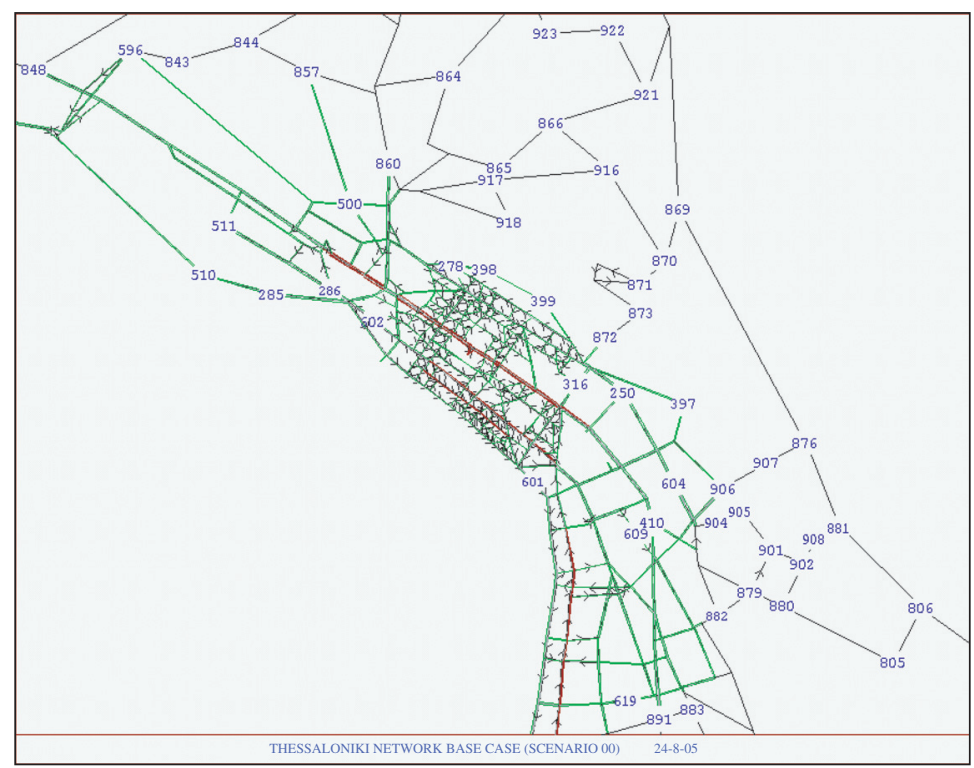

Figure 1: Graphic representation of Thessaloniki's network area modelled and exported by the SATURN module P1X. 
Table 2: Attributes of Thessaloniki's road charging implementation scheme.

\begin{tabular}{lcl}
\hline Attribute & Units & \multicolumn{1}{c}{ Preliminary stage } \\
\hline Pricing method & - & Cordon Tolls \\
Implementation area & - & City Business Centre \\
Area & $\mathrm{km}^{2}$ & 0.825 \\
Fee collection and enforcement & - & ATCS and ANPR \\
Number of main gates & - & 5 \\
Free of charge & - & Public transport and clean fuelled vehicles \\
Fee & Euro & 2.2 \\
Days of operation & Day & Morning peak hour - weekdays \\
\hline
\end{tabular}

trans-modal transport pricing, towards achieving an optimum modal split in urban areas, at the pan-European level. The project was based on actions and analyses in eight European cities - Athens, Madrid, Como, Leeds, York, Goteborg, Helsinki and Graz - covering a wide range of urban areas, in terms of both geography and typology. Demonstration of pricing measures using real-life applications and limited initial experimental field trials of systems and measures was carried out in Athens, Como, Madrid, Leeds and York. The potential changes in travel behaviour due to pricing measures were assessed by means of a Stated Preference (SP) survey in all eight sites [5].

This was the first time that such a survey had been applied to several urban areas with a common experimental design. The analysis of the SP survey gave estimates of Value of Time (VoT) and mode-specific constants. The survey also included acceptability questions on the justification of road use pricing, the preferred allocation of revenues and the preferred method of payment.

In Athens the results of the road use pricing trial indicated that $25 \%$ of car users transferred to Park and Ride, $5.5 \%$ to Public Transport and $0.5 \%$ to other modes, for a mean charge level of 1.8 euro. This means that almost $31 \%$ of the trips, which are materialized by car and cause traffic congestion to the city roads, could be transferred to public transport, improving the network operation and reducing the associated environmental problems [5].

The value of 1.8 euro was used as a fee charge for the road pricing scenarios in the Thessaloniki Metropolitan Area, adding a mean yearly inflation of 3.5\%, from the year of TransPrice's publication (2000) to the base case year of the study (2004). Moreover, it was assumed that the $31 \%$ change in the modal split could affect only the through-traffic trips in Thessaloniki, which were estimated to be about $25 \%$ of the total daily trips, as mentioned above.

Another main study whose results were used as data inputs to this research was the GTS of the Thessaloniki Metropolitan Area. This large-scale research contained, among others, detailed surveys in order to estimate the traffic volumes on the city roads during morning and evening peak hours [7].

A set of morning counts were used as calibration counts for the validation in order to assess the reliability of the model. The selection of these observation counts was done in order to represent low, middle and high rates of traffic counts. The results were totally acceptable especially for the low and the middle rates of traffic counts, with a correlation coefficient of $R^{2}=0.966$ between the modelled and the observed flows, and their general regression analysis function is given by:

$$
Y=-229,616+1,095 X \text {. }
$$

The regression function is presented in Fig. 2. 


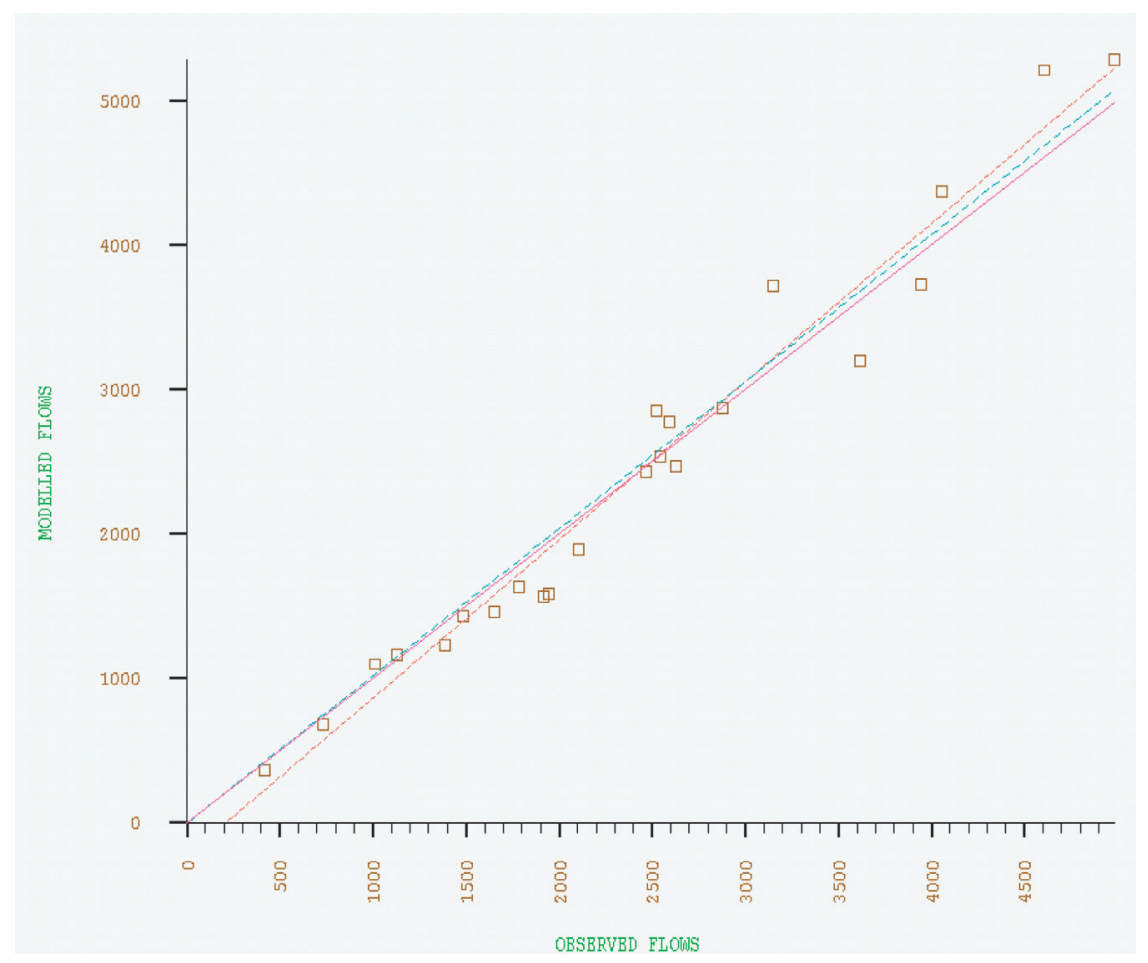

Figure 2: The regression function of Thessaloniki's traffic simulation model for the observed and modelled flows.

\section{SCENARIOS TESTED}

The calibrated simulation model of the site was used to develop potential scenarios for testing and evaluating the performance of the road pricing management strategies. Figure 3 shows the seven scenarios that were developed in total, plus their respective codes used by the traffic simulation model.

\subsection{The 'Cordon Road Charging' scenarios}

These scenarios were developed in order to assess and evaluate the traffic and the associated environmental impacts, plus the revenues of the implementation of a cordon pricing scheme in the city centre.

The 1 zone scenario was developed in order to assess the impacts described 'before' and 'after' the implementation of a road toll pricing scheme in the City Business Center (CBC). Figure 4 shows a general representation of the road charging implementation area (zone 1), indicated by the streets Aggelaki, Egnatia, I. Dragoumi, L. Nikis and N. Germanou. Apart from that, this scenario was used as the base case for the evaluation of the 2 zones and the $1+1$ zones scenarios. The main attributes of the implementation scheme are presented in Table 2.

The 2 zones scenario pertains to an expanding charging network, with the second zone surrounding the first, as indicated in Fig. 4 (zone 2). The charge fee for the first zone was defined at 1.8 euro and for the second zone at 0.4 euro assuming that the generalized cost for the through-traffic trips, 


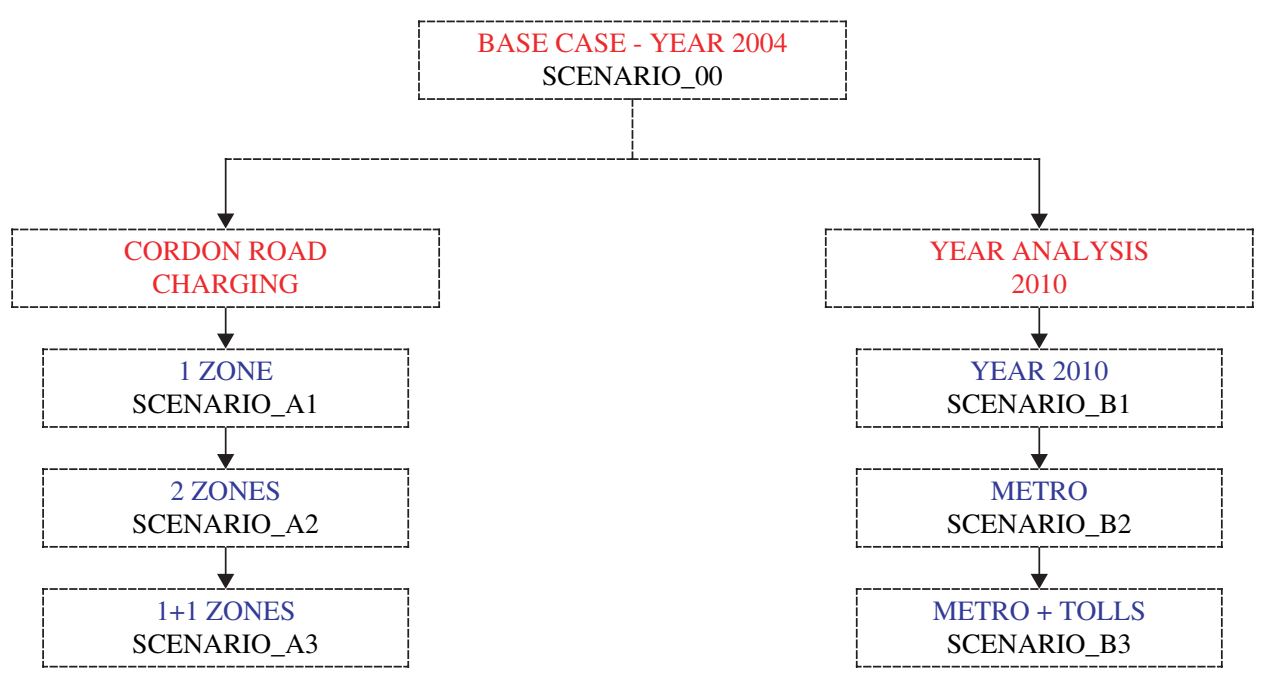

Figure 3: Thessaloniki's urban toll scenarios.

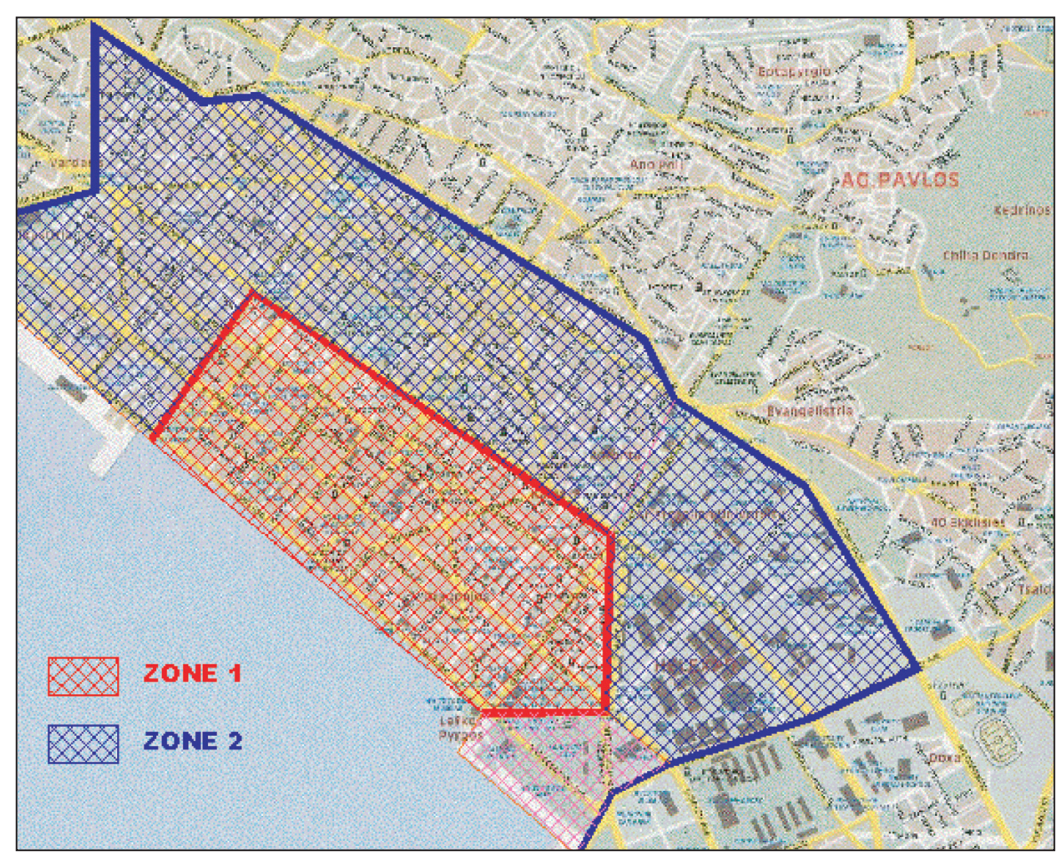

Figure 4: The two zones of cordon charging.

which are responsible for the congestion in the area, remains the same (aggregation 2.2 euro). It was assumed at that point that there would not be any change in travel behaviour and modal split.

The $1+1$ zones scenario assumes that although the fee for the initial zone is 2.2 euros and for the second zone is 0.4 euro, there is no change of modal split. This hypothetical scenario was developed in order to estimate the impacts of such an implementation, taking into account that the inhabitants 
are not used to being charged for the use of the road infrastructure (so they are not willing to change their travel mode or destination).

\subsection{The Year 2010 Analysis scenarios}

These scenarios describe and evaluate Thessaloniki's road network in the year 2010, which is expected to be the first year of operation of the metro transportation system.

The Year 2010 scenario is a 'Do-Minimum' scenario, assuming that unpredicted factors might have extended the construction period of the metro transportation system. Although there will not be any new infrastructure, the daily trips are estimated to have an average growth of $6 \%$ for the construction period 2004-2010.

The Metro scenario introduces the operation of the metro system. The change in modal split, because of the operation of the new mode, was estimated by the GTS using hierarchical logit model techniques. The results are presented in Fig. 5, showing that almost $7 \%$ of the total daily trips will materialize through the new mode without assigning the road infrastructure (no participation in the model assignment procedure). When the purpose of the trips was park and ride, the trips were not included in this research. It must be mentioned that the GTS also excluded park and ride trips from the results, assuming that these trips do not significantly affect the study area (CBC) [7].

Finally, the Metro and Tolls scenario analyses the simultaneous operation of the metro transportation system and the implementation of a cordon pricing scheme. The change in the modal split resulted as the aggregation of the two separate implementations (metro and tolls).

It is important to clarify that the changes in modal split correspond to variations of the trip matrix model file, as some trips do not participate in the assignment procedure. The change and the analysis of the trip matrix can be easily achieved by the SATURN module MX (Matrix Manipulation). MX is a flexible interactive matrix manipulation program which incorporates virtually all matrix operations required by SATURN users. In this research, the new (internal) matrices were created based on FORTRAN syntax functions, a technique which easily allows matrix manipulation [13].

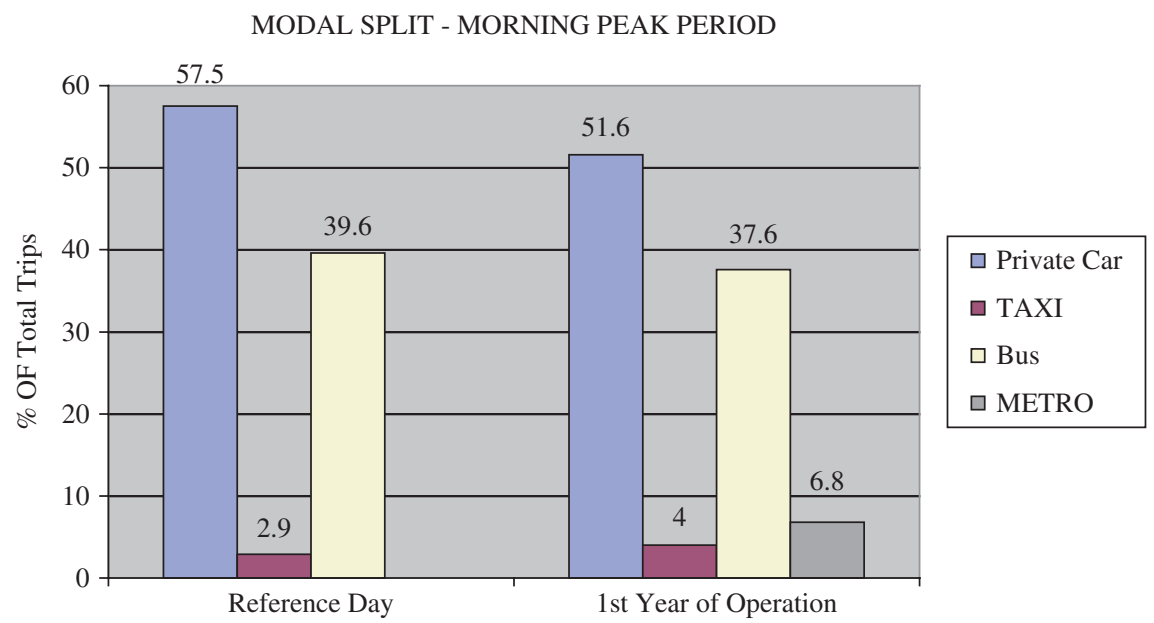

Figure 5: Modal split 'before' and 'after' metro's operation [7]. 


\section{COMPARATIVE EVALUATION}

For the analysis and the comparison of the scenarios described above, various techniques were chosen, including the graphic representation of the selected parameters by P1X, with respect to:

1. the general network in total;

2. the cordon toll implementation area;

3. specific transportation, environmental and financial characteristics.

For the overall network as well as the cordon area, several indices were examined including over-capacity queues, total travel time, overall average speed, fuel consumption and momentary tolls (Fig. 6a), along with various environmental parameters such as $\mathrm{CO}, \mathrm{CO}_{2}, \mathrm{NO}_{x}, \mathrm{HC}, \mathrm{Pb}, \mathrm{PM}_{10}$ (Fig. 6b).

Another alternative option, which allows the assessment of the impacts of the scenarios developed, is the analysis using the P1X module. Two techniques were used for the purposes of the present analysis - 'isochronous curves' and the well-known 'V/C Roadway Level of Service'.

The 'isochronous curves' technique, which is still very much under development, displays equicost bands from the origin as overlapping in-filled coloured bands. These are based not just on the costs from the origin to discrete points along the road but to any point in the two-dimensional space within the network by the additional assumption of a 'walking speed'. Thus, the cost to reach any point $(X, Y)$ consists of the cost to get to the 'nearest' point on the road network plus the extra time/ cost to 'walk' from the road (assuming the minimum crow fly distance) [13]. According to the shape and dimension of the curve, it is easy to extract useful conclusions about the network operation before and after an implementation. Figure 7(a) represents the isochronous curve before (Scenario_00) and after (Scenario_A1) the road charging operation. The origin point is zone 113, within the CBC area and the number of the colour intervals is six.

The second technique refers to the Volume/Capacity (V/C) ratio Level of Service, displayed with 'Bandwidth' coloured circles. Information related to nodes or junctions may be included within network plots via various modes, which display a variety of numerical and/or geometric information, such as V/C [13]. In this research, four colour intervals were used, with the first (green colour) corresponding to $\mathrm{V} / \mathrm{C}$ values up to $60 \%$ and the second (red colour) above $100 \%$. The radius of the circle was equal to $20 \mathrm{~m} / \mathrm{unit}$. Figure 7(b) shows the V/C Level of Service for each node of the study area, for the previous scenarios (_00 and_A1).

\section{RESULTS}

The outcomes of the research are divided into quantitative and qualitative results according to the model calculations and general conclusions of the study, respectively.

\subsection{Quantitative results}

With respect to Thessaloniki's urban toll implementation case, the running of the mathematical model provided the following quantitative results:

- There is a total need for the implementation of major TDM measures such as road pricing. If the current situation remains unchanged, it was estimated that the study parameters would get worse by $20 \%$ until 2010.

- The introduction of a charge fee for road use $(1$ zone) can improve the network parameters in total, by about $25 \%$. More specifically, the over-capacity queues which sometimes lead to 
(a)

\begin{tabular}{|c|c|c|c|c|c|c|c|}
\hline \multicolumn{8}{|c|}{ OVERALL NETWORK STATISTICS FOR THE ROAD CHARGING SCENARIOS } \\
\hline \multirow{2}{*}{ PARAMETERS } & Scenario_00 & Scenario_A1 & \multicolumn{2}{|c|}{ Scenario_A2 } & \multicolumn{2}{c|}{ Scenario_A3 } \\
\cline { 2 - 8 } & Value & Value & $\%$ & Value & $\%$ & Value & $\%$ \\
\hline OVER-CAPACITY QUEUE & 12164.2 & 8303.7 & -31.74 & 7867 & -5.26 & 7752.7 & -6.64 \\
\hline TOTAL TRAVEL TIME & 18209.8 & 13843 & -23.98 & 13301.6 & -3.91 & 13159.1 & -4.94 \\
\hline OVERALL AVERAGE SPEED & 9.3 & 11.2 & 20.43 & 11.5 & 2.68 & 11.5 & 2.68 \\
\hline FUEL CONSUMPTION & 47449.1 & 38788.3 & -18.25 & 37629.1 & -2.99 & 37236.6 & -4.00 \\
\hline MOMENTARY TOLLS & - & 15337.1 & - & 21869.4 & 42.59 & 23930.6 & 56.03 \\
\hline
\end{tabular}

(b)

\section{VEHICLE EMMISIONS}

OVERALL NETWORK- YEAR ANALYSIS 2010

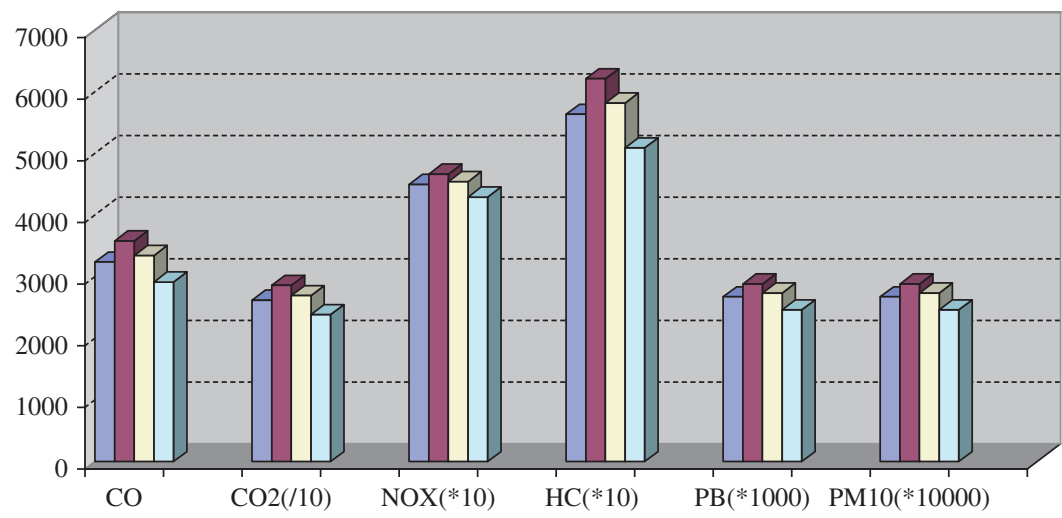

$\square$ Scenario_00

- Scenario_B1

$\square$ Scenario_B2

$\square$ Scenario_B3

Figure 6: Transportation (a) and environmental (b) parameters for the evaluation of the scenarios tested.

congestion phenomena seem to be significantly reduced by about $30 \%$. Another prominent outcome is the reduction of the total travel time (25\%) together with fuel consumption (20\%).

- The operation of the metro system will temporally improve (average level of 12\%) the network indices, although the simultaneous implementation of a road charging scheme could be a more effective and efficient solution.

- The scenarios with 2 zones of charging slightly improve the overall network operation (except the momentary incomes), but can significantly improve the traffic condition within the cordon area $(\mathrm{CBC})$.

- Vehicle emissions varied similarly with the traffic parameters, with hydrocarbon (HC) indices having the widest range.

- The analysis and assessment using the P1X module could be useful for understanding the road network operation. One useful conclusion is that the road charge fee can significantly improve the traffic conditions at the main city corridors like Egnatia St. and Tsimiski St. 


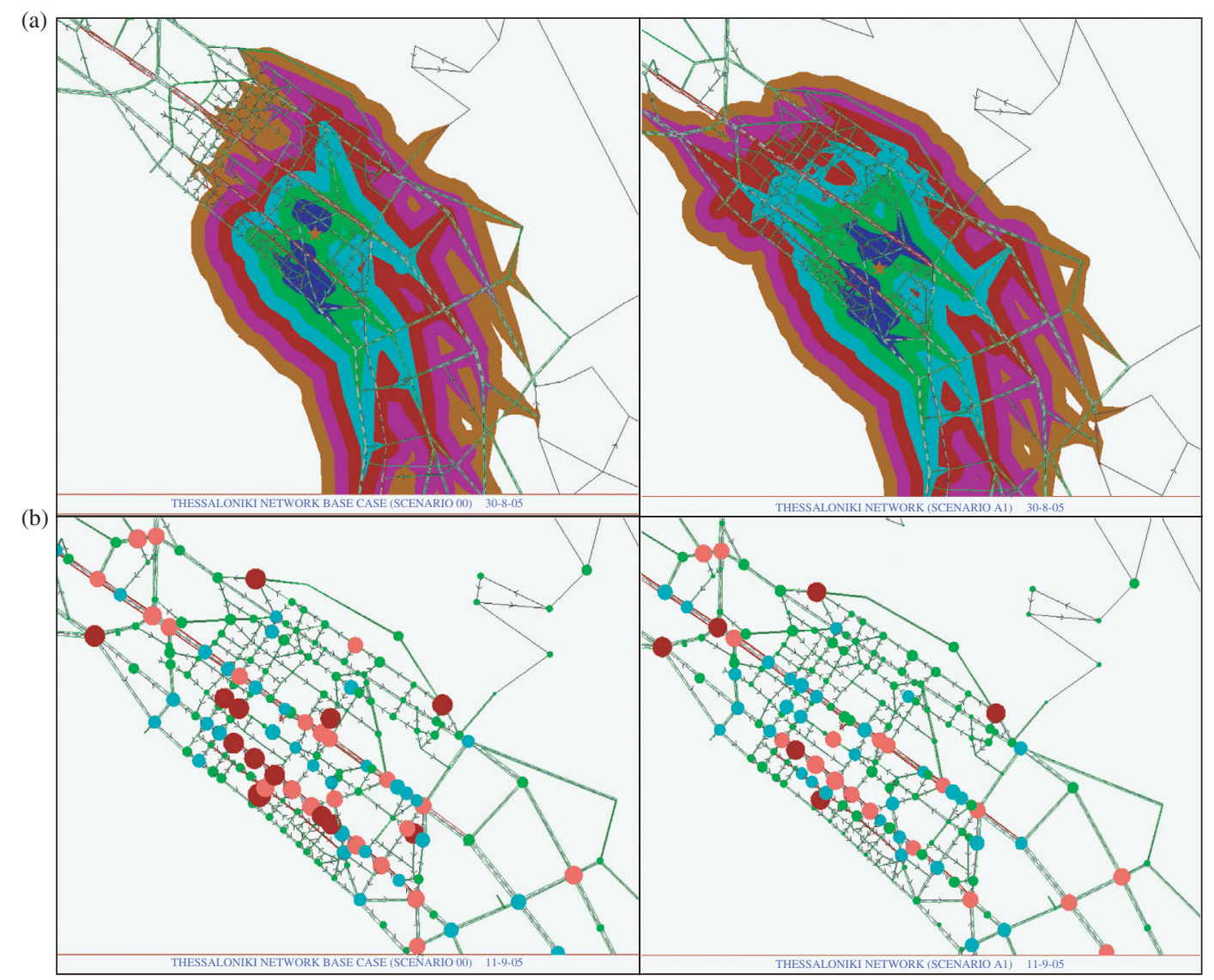

Figure 7: Isochronous curves (a) and V/C Level of Service (b) 'before' and 'after' the road pricing implementation.

\subsection{Qualitative results}

The qualitative results include outcomes and comments that satisfy the goals of sustainable development as described in Section 1. More specifically, the analysis is focused on the subcategories presented in Table 1. The improvement of the network operation (as evidenced by the decrease of over-capacity queues, the total travel time and the fuel consumption together with the increase in average speed) affects a series of subcategories presented in the Table 1 .

- First, at the economic level, it is clear that a more sufficient road transport network can point to more 'affordable' and 'productive' communities, increasing potentially 'trade and business activity' and 'employment'. Furthermore, fuel consumption as well as the decrease in emissions together with the existence of momentary incomes contribute to 'cost internalization' of the transport system operation.

- Obviously, this internalization influences the social perspective of people's activity. 'Social equity', 'human health' and 'quality of life' are some of the subcategories in Table 1 that seem 
Table 3: The satisfaction of sustainability goals through a road charging scheme.

\begin{tabular}{lll}
\hline Economic & \multicolumn{1}{c}{ Social } & \multicolumn{1}{c}{ Environmental } \\
\hline Affordability (1) & Equity (1) & Pollution prevention (1) \\
Resource efficiency (1) & Human health (1) & Climate protection (2) \\
Cost internalization (1) & Education (3) & Biodiversity (3) \\
Trade and business activity (1) & Community (1) & Precautionary action (2) \\
Employment (1) & Quality of life (1) & Avoidance of irreversibility (2) \\
Productivity (1) & Public participation (2) & Habitat preservation (3) \\
\hline
\end{tabular}

(1): Satisfied; (2): under presupposition; (3): not satisfied.

to be satisfied by the implementation of schemes such as urban tolls. Moreover, if the planning of these measures is conducted in a proper and coordinated way, then it is possible that these initiatives could increase the 'public participation'.

- Finally, fuel consumption and emissions results can satisfy a series of subcategories at the environmental level such as 'pollution prevention', 'climate protection', 'avoidance of irreversibility'.

The qualitative results are summarized in Table 3, which indicates that, under preconditions, the implementation of a road charging scheme, such as urban tolls, can not only improve the operation of a highly congested network, but it can also be considered as a measure that satisfies many aspects of sustainability.

\section{RECOMMENDATIONS}

Urban tolls is a 'third-generation' TDM measure that is suitable for major metropolitan areas; it is preferred after the integrated implementation of 'first-generation' measures such as the promotion public transport, the step-up of transport infrastructure through extension or establishment of new lanes and 'second-generation' measures such as park management, priority to public transit [14].

Through the analysis and evaluation of the scenarios tested for the purposes of the present research, five basic suggestions can be made:

1. The operation of a road charging system must be accompanied with a high-class public transport system, acting as an alternative mode. A successful public transport system should provide a level of accessibility that is as efficient as the level provided by private cars (if possible). Also, the implementation of such measures should be part of an integrated traffic management policy. In the case of the city of Thessaloniki, the most important preconditions that can result in a road charging trial becoming a successful and sustainable traffic management measure are the following:

- The existence of an integrated city parking policy, including management and enforcement issues.

- The materialization of the major transport projects described above (metro system and submerged tunnel) and the elaboration of their operation framework in order to work complementarily and not competitively with the other public transport systems.

2. The planning and successful operation of a road charging scheme require:

- The completion of the period needed for the project maturation not only in terms of technocratic issues (e.g. cordon area for charging) but also in terms of issues related to users' acceptance, possible objections by the non-users and financial support. 
- The utilization of international experience (know-how), especially for the last stage of the planning process. Another major factor is the existence of a continuous evaluation and re-planning of the project, taking into account the traffic and land use characteristics.

3. The operation of such TDM measures presupposes the establishment of a Manager Operator Authority. Without any doubt, the existence of Thessaloniki's Metropolitan Coordinate Council (S.A.S.Th.), which is responsible for the optimal development and utilization of transportation infrastructure of the city, could be the initial base for the formation of such a policy institution.

4. Within the framework of this Operator Authority the involvement of scientists from various backgrounds, like transportation engineers, urban and regional planners, transport psychologists, is essential.

5. The only experience in Greece, concerning urban tolls, comes from the operation of Attiki Odos (Attika Tollway) in Athens. Another similar application could be the operation of the submerged tunnel in Thessaloniki in the coming years. The method of operation, the evaluation and the possible positive contribution of these projects to people's everyday lives should be disseminated to users in order to be informed about the advantages of such middle- and large-scale TDM applications (transferability of results).

Finally, the evaluation showed that the implementation of a road pricing scheme could significantly improve Thessaloniki's road network and reduce the associated environmental problems. Moreover, it was shown that such a measure can yield broader benefits in terms of sustainability. The finally accepted definition of sustainability, which was presented in the framework of this paper, seems to be satisfied through the installation and operation of an urban toll scheme in the study area. Nevertheless, there is a lot to be done for the above-mentioned modelling scenarios to materialize as real-life applications and successful strategy. One major aspect is that these policies must be embedded in a greater master plan and designed in a coordinated way in order to optimize the potential benefits. There is no doubt that similar approaches are moving towards the main targets of the European Community concerning sustainable mobility end efficiency in major metropolitan areas such as the city of Thessaloniki [15].

\section{REFERENCES}

[1] Shepherd, S.P., Zhang, X., Emberger, G., Hudson, M., May, A.D. \& Paulley, N., Designing optimal urban transport strategies: the role of individual policy instruments and the impact of financial constraints. Transport Policy, 13, pp. 49-65, 2006.

[2] Victoria Transport Policy Institute, Sustainable transportation and TDM: planning that balances economic, social and ecological objectives. Online TDM Encyclopedia, updated 9 May 2005, available at www.vtpi.org.

[3] Goldman, T. \& Gorham, R., Sustainable urban transport: four innovative directions. Technology in Society, 28, pp. 261-273, 2006.

[4] Litman, T., Well Measured: Developing Indicators for Comprehensive and Sustainable Transport Planning, Victoria Transport Policy Institute: Canada, June 2005.

[5] TransPrice (Trans-Modal Integrated Urban Transport Pricing for Optimum Modal Split), Final Report for Publication, December 1999.

[6] Wong, W., Noland, R. \& Bell, M., The theory and the practice of congestion pricing. Transportation Research Part A, 39, pp. 567-570, 2005.

[7] Organization for the Master Plan and Environmental Protection of Thessaloniki, General Transport Study (GTS) of Thessaloniki Metropolitan Area, Denco, Trademco, Infodim, Aggelidis, Truth, SDG, WS-Atkins, Thessaloniki, Greece, 2000. 
[8] Urban Transport Organization of Thessaloniki website, www.oasth.gr.

[9] IMPRINT-EUROPE (Implementing Reform in Transport Effective Use of Research on Pricing in Europe), Road Pricing Singapore's Experience, Brussels, October 2002.

[10] Orange County Transportation Authority, Success in the Fast Lanes - Fiscal Year 2004, Annual Report, January 2005.

[11] Litman, T., London Congestion Pricing - Implications to Other Cities, Victoria Transport Policy Institute: Canada, February 2004.

[12] Shaffer, B. \& Santos, G., Preliminary Results of the London Congestion Charging Scheme, Paper no. 04-3979, November 2003.

[13] Van Vliet, D., SATURN v10.4 - User Manual, Institute for Transport Studies, University of Leeds, Leeds, UK, July 2003.

[14] Hellenic Institute of Transportation Engineers (H.I.T.E.), The Aspects of H.I.T.E. on the Occasion of Completion of 25 Years of the Institute's Establishment, Athens, July 2003.

[15] PROGRESS Project (Pricing Road Use for Greater Responsibility, Efficiency and Sustainable in Cities), Main Project Report, Version 1.0, July 2004. 